\title{
Isolation and Study of Abies Bark Proanthocyanidins
}

\author{
Vladimir A. Levdansky*, Alexander A. Kondrasenko, \\ Alexander V. Levdansky and Maxim A. Lutoshkin \\ Institute of Chemistry and Chemical Technology SB RAS \\ FRC "Krasnoyarsk Science Center SB RAS" \\ 50/24 Akademgorodok, Krasnoyarsk, 660036, Russia
}

Received 16.09.2019, received in revised form 19.10.2019, accepted 20.11.2019

\begin{abstract}
The process of proanthocyanidins isolation from abies bark by water and water-alcohol solutions containing 5, 10, 15 and $20 \%$ ethanol was studied for the first time. The optimal conditions providing the maximum yield of proanthocyanidins were determined experimentally. It was shown that the use of 15-20\% water-alcohol solutions allows to increase the yield of proanthocyanidins from 0.33 to $0.38 \%$. The composition of the obtained proanthocyanidins was studied by $U V, I R$, and ${ }^{13} C N M R$ spectroscopy. The obtained proanthocyanidins were transformed into colored anthocyanidins in ethanol medium in the presence of hydrochloric acid. The flavonoids cyanidin and delphinidin were isolated and identified. It was established that the obtained proanthocyanidins mainly consist of procyanidin and prodelphinidin. It was shown that proanthocyanidins obtained from abies bark, in contrast to the proanthocyanidins isolated from pine bark described in the literature, contain gallic acid residues, which is typical for proanthocyanidins isolated from various types of tea.
\end{abstract}

Keyword: abies bark, extraction, proanthocyanidins, procyanidin, prodelphinidin, gallic acid, ethanol, hydrochloric acid, cyanidin, delphinidin.

Citation: Levdansky V.A., Kondrasenko A.A., Levdansky A.V., Lutoshkin M.A. Isolation and study of abies bark proanthocyanidins, J. Sib. Fed. Univ. Chem., 2019, 12(4), 604-613. DOI: 10.17516/1998-2836-0155. 


\title{
Выделение и изучение \\ проантоцианидинов коры пихты
}

\author{
В.А. Левданский, А.А. Кондрасенко, \\ А.В. Левданский, М.А. Лутошкин \\ Институт химии и химической технологии СО РАН \\ ФИЦ «Красноярский научный центр СО РАН» \\ Россия, 660036, Красноярск, Академгородок, 50/24
}

\begin{abstract}
Впервые изучено выделение проантоцианидинов из коры пихты водой и водно-спиртовыми растворами, содержащими 5, 10, 15 и 20 \% этанола. Экспериментальным путем определены оптимальные условия, обеспечивающие максимальный выход проантоцианидинов. Показано, что использование 15-20\% водно-спиртовых растворов позволяет увеличить выход проантоцианидинов с 0.33 до $0.38 \%$. Методами УФ-, ИК- и ${ }^{13}$ С ЯМР-спектроскопии изучен состав полученных проантоцианидинов. Путем превращения последних в этаноле в присутствии соляной кислоты в окраменные антоцианидины выделены и идентифицированы флавоноиды ичиандин и дельфинидин. Установлено, что полученные проантоцианидины в основном состоят из процианидина и продельфинидина. Показано, что проантоциианидины из коры пихты в отличие от описанных в литературе проантоцианидинов, выделяемых из коры сосны, содержат остатки галловой кислоты, что присуще проантоцианидинам, выделяемым из различных видов чая.
\end{abstract}

Ключевые слова: кора пихты, экстракцุия, проантоциианидины, процианидин, продельфинидин, галловая кислота, этанол, соляная кислота, цииандин, дельфинидин.

\section{Введение}

Полифенольные соединения - одна из самых многочисленных и распространенных групп природных веществ, привлекающих внимание благодаря широкому спектру их биологической активности [1]. Олигомерные проатоцианидины - одни из самых интересных и важных для человека представителей растительных полифенольных соединений. Главное отличие проантоцианидинов от остальных полифенольных соединений в том, что они составляют основную (до 80 \%) часть потребляемых человеком биофлавоноидов. Ими богаты растения, фрукты и натуральные напитки, которые использовались человеком в значительных количествах с незапамятных времен. Употребление вина, например, насчитывает уже более 6000 лет. Кроме вина в список продуктов питания, богатых проантоцианидинами и мономерными катехинами, входят виноград, яблоки, бобы, пшеница, а также какао, кофе, яблочный сидр, чай всех видов [2]. Согласно статистическим данным, ежедневное потребление биофлавоноидов с растительной пищей в европейских странах достигает 1.5 г [3]. Основную часть от этого количества составляют проантоцианидины и их мономерные звенья - катехины и эпикатехины, так как только эти соединения флавоноидной природы способны образовывать полимерные структуры.

$$
-605-
$$


Важность проантоцианидинов как компонента здорового питания обусловила выделение очищенных комплексов проантоцианидинов в качестве биологически активных добавок к пище. В США созданы административные органы, регулирующие их качество и употребление [1].

По химическому строению проантоцианидины относятся к одной из групп фенольных веществ. Они представляют собой полимерные флаван-3-олы, которые имеют С6-С3-С6флавоноидный скелет. Проантоцианидины существуют в виде растворимых в воде олигомеров, содержащих от 2 до 6 катехиновых единиц, а также в виде нерастворимых в воде полимеров со степенью порлимеризации от 7 и выше, которые представляют собой основную (80 \%) часть проантоцианидиновых комплексов $[2,3]$.

Наиболее широко в пищевых продуктах растительного происхождения распространены димерные проантоцианидины с расположением гидроксильных групп в положении 3',4' и проантоцианидины с 3',4',5' гидроксизамещением в кольце В. Наиболее характерным примером димерных проантоцианидинов могут служить проантоцианидины B-1, В-2 и В-4, образующиеся на основе (-)-эпикатехина и (+)-катехина. Проантоцианидин В-3 встречается реже, он присутствует в малине и черной смородине. Помимо димерных проантоцианидинов известны также димерные продельфинидины (рис. 1) [1-3].

Проантоцианидины представляют значительный интерес для современной медицины как группа биологически активных веществ, обладающих разнообразной фармакологической активностью: антиоксидантной, противовоспалительной, антиаритмической и гипотензивной [4-6].

Цель работы - поиск оптимальных условий извлечения проантоцианидинов из коры пихты сибирской и их идентификация.
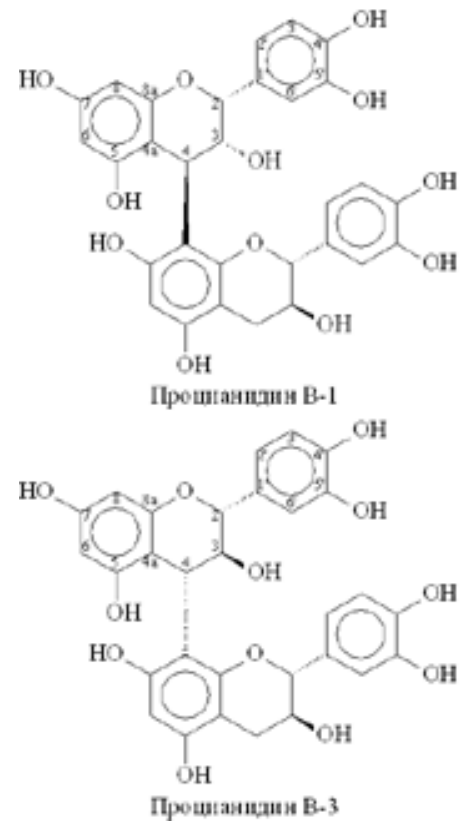

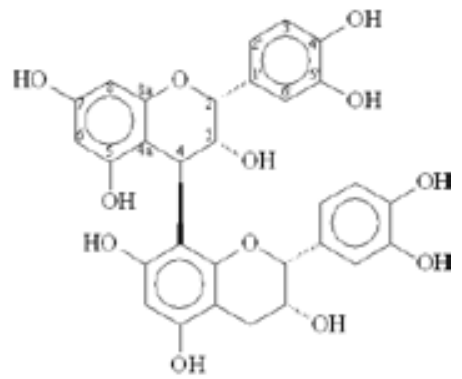

Процианпдин В-2

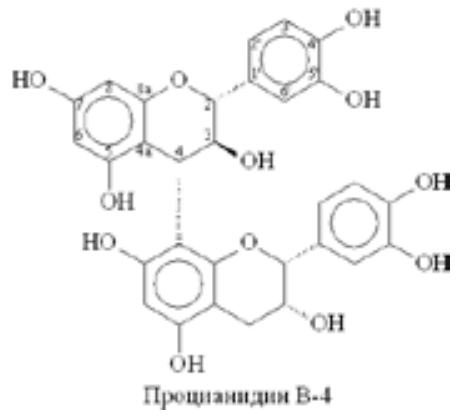

Рис. 1. Димерные процианидины

Fig. 1. Dimeric procyanidins 


\section{Экспериментальная часть}

В качестве исходного сырья использовали кору пихты сибирской (Abies sibirica Ledeb.), заготовленную в феврале 2019 г. в окрестностях г. Красноярска. Образцы коры отбирали с одновозрастных (45-50 лет) пихт на расстоянии 1-2 м от комля. Перед использованием кору высушивали при температуре $100 \pm 5^{\circ} \mathrm{C}$ в течение 5-6 ч, измельчали, после просеивания отбирали фракцию от 1 до 2 мм, досушивали ее до постоянного веса. Химический состав коры пихты определяли по общепринятым в химии древесины методикам [7]. Содержание основных компонентов коры пихты ( \% от массы а.с. коры): целлюлоза - 23.9, лигнин - 36.9, экстрактивные вещества - 18.3, легкогидролизуемые полисахариды - 17.2, трудногидролизуемые полисахариды - 23.0, зольность - 1.9 .

Высушенную и измельченную кору экстрагировали гексаном в течение 24 ч в аппарате Сокслета емкостью 1 л для выделения смолистых веществ. Выход смолистых веществ $9.0 \pm 0.5 \%$ от массы а.с. коры.

\section{Выделение проантоцианидинов.}

В круглодонную колбу объемом 2 л, снабженную мешалкой и обратным холодильником, загружают 100.0 г коры пихты сибирской, измельченной до частиц 1-2 мм и предварительно проэкстрагированной гексаном, заливают 1.5 л дистиллированной воды и кипятят при интенсивном перемешивании в течение 1.0 ч, затем горячий водный раствор отделяют фильтрованием и получают 1.1-1.2 л экстракта. Экстракт концентрируют под вакуумом на ротационном испарителе до 350-400 мл и насыщают хлоридом натрия, образующийся осадок полифенольных веществ отделяют фильтрованием. Фильтрат трижды экстрагируют, используя по 200 мл этилацетата, сушат над безводным сульфатом натрия, затем этилацетатный раствор концентрируют под вакуумом до объема 50-60 мл и разбавляют в 7-8 раз хлороформом; при этом проантоцианидины выпадают в осадок в виде белых хлопьев, их отделяют фильтрованием. Выход проантоцианидинов составил 0.33 г ( $0.33 \%$ ) от массы исходной коры. В аналогичных условиях проводили извлечение проантоцианидинов водно-спиртовыми растворами, содержащими 5, 10, 15 и 20 \% этанола.

ИК-спектры проантоцианидинов снимали с использованием ИК-Фурье-спектрометра Tensor-27 (Bruker, Германия) в области длин волн 400-4000 см-1. Обработку спектральной информации проводили по программе OPUS (версия 5.0). Твердые образцы для анализа готовили в виде таблеток в матрице $\mathrm{KBr}$ (2 мг образца / 1000 мг KBr).

ЯМР ${ }^{13} \mathrm{C}$-спектры проантоцианидинов сняты в $\left(\mathrm{CD}_{3}\right)_{2} \mathrm{DO}$ при температуре $25{ }^{\circ} \mathrm{C}$ с использованием спектрометра Bruker Avance III 600 МГц с привязкой к дейтериевому резонансу растворителя.

Проантоцианидины превращали в антоцианидины известным методом - нагреванием в этаноле в присутствии соляной кислоты $[8,9]$. Для разделения смеси антоцианидинов применяли колоночную хроматографию на полиамидном сорбенте. Элюирование проводили 96\%-ным этанолом, содержащим 0.01 соляной кислоты. По ходу движения элюента по колонке наблюдали две четко выраженные зоны окрашивания. После отбора фракций и концентрирования под вакуумом их анализировали методом УФ-спектроскопии.

Электронные спектры поглощения полученных проб записаны на сканирующем УФспектрометре Leki SS2109-UV (Leki Instruments, Финляндия) в 1 см кварцевой кювете в диа-

$$
-607-
$$


пазоне длин волн $600-450$ нм. Термостатирование $\left( \pm 0.1^{\circ} \mathrm{C}\right)$ проводили с помощью термостата Haake K15, оснащенного контроллером Haake DC10, при температуре $20^{\circ} \mathrm{C}$. Спектры образцов были сняты одномоментно при выделении из колонки без дополнительной очистки. Все спектры образцов были получены в этаноле с содержанием воды не более 10 \%.

\section{Результаты и обсуждение}

В последнее время в качестве антиоксидантов успешно применяют комплексы олигомерных проантоцианидинов (КОПЦ). В основе данных комплексов лежат две мономерные единицы - катехин и эпикатехин, а также их галлоильные производные. Благодаря способности этих соединений образовывать полимерные структуры из двух и более субъединиц формируются КОПЦ $[4,8]$. Источниками промышленного получения КОПЦ являются косточки винограда (Vitis vinifera) и кора сосны [4, 8-10]. КОПЦ, получаемый из коры сосны, в отличие от получаемого из косточек винограда стабилен по своему составу, так как для производства используется сырье одного вида и один способ извлечения [4].

В настоящее время кора сосны является основным источником получения проантоцианидинов. Они выпускаются под названием «Пикногенол» и «Энзогенол». Пикногенол получают экстракцией коры сосны водой и последующей очисткой водного экстракта органическими растворителями, а энзогенол - экстракцией коры сосны только водой. Выход пикногенола составляет $0.2-0.3 \%$, а энзогенола $-0.5 \%$ [10].

Выделение проантоцианидинов из коры пихты проводили водой и водно-спиртовыми растворами. Данные о влиянии концентрации этанола в водно-этанольной смеси на выход экстрагируемых из коры пихты проантоцианидинов приведены в табл. 1.

Как следует из полученных данных, при увеличении концентрации этанола в смеси до 20 \% выход проантоцианидинов увеличивается с 0.33 до 0.38 \% масс. При дальнейшем повышении концентрации этанола выход проантоцианидинов не увеличивается. Однако увеличение концентрации этанола более 20 \% приводит к увеличению общего выхода экстрактивных веществ за счет дополнительного извлечения высокомолекулярных полифенолов. Дополнительно извлекаемые полифенолы удаляются в процессе очистки проантоцианидинов при насыщении экстракционного раствора хлоридом натрия и не влияют на выход проантоцианидинов.

ИК-спектры проантоцианидинов, выделенных водой (рис. 2) и 15\%-ным водно-этанольным раствором (рис. 3), идентичны.

Таблица 1. Влияние концентрации этанола в водно-этанольной смеси на выход проантоцианидинов из коры пихты

Table 1. The effect of the concentration of ethanol in the water-ethanol mixture on the yield of proanthocyanidins from abies bark

\begin{tabular}{|c|c|c|c|c|}
\hline \multicolumn{5}{|c|}{ Концентрация этанола, \% } \\
\hline 0 & 5 & 10 & 15 & 20 \\
\hline \multicolumn{5}{|c|}{ Выход проантоцианидинов, \% от массы а.с. коры } \\
\hline $0.32-0.33$ & $0.33-0.34$ & $0.34-0.36$ & $0.36-0.38$ & $0.37-0.38$ \\
\hline
\end{tabular}


Изучали полученные из коры пихты проантоцианидины с помощью методов УФ-, ИК- и ${ }^{13}$ С ЯМР-спектроскопии.

Проведен сравнительный анализ ИК-спектров проантоцианидинов, выделенных из коры пихты (рис. 2, 3), и проантоцианидинов из коры сосны обыкновенной [8], а также спектров проантоцианидинов, описанных в работах $[11,12]$.

В ИК-спектре проантоцианидинов из коры пихты присутствуют все полосы поглощения, характерные для проантоцианидинов коры сосны, в области 3400-3385, 1612-1607, 1522-1514,

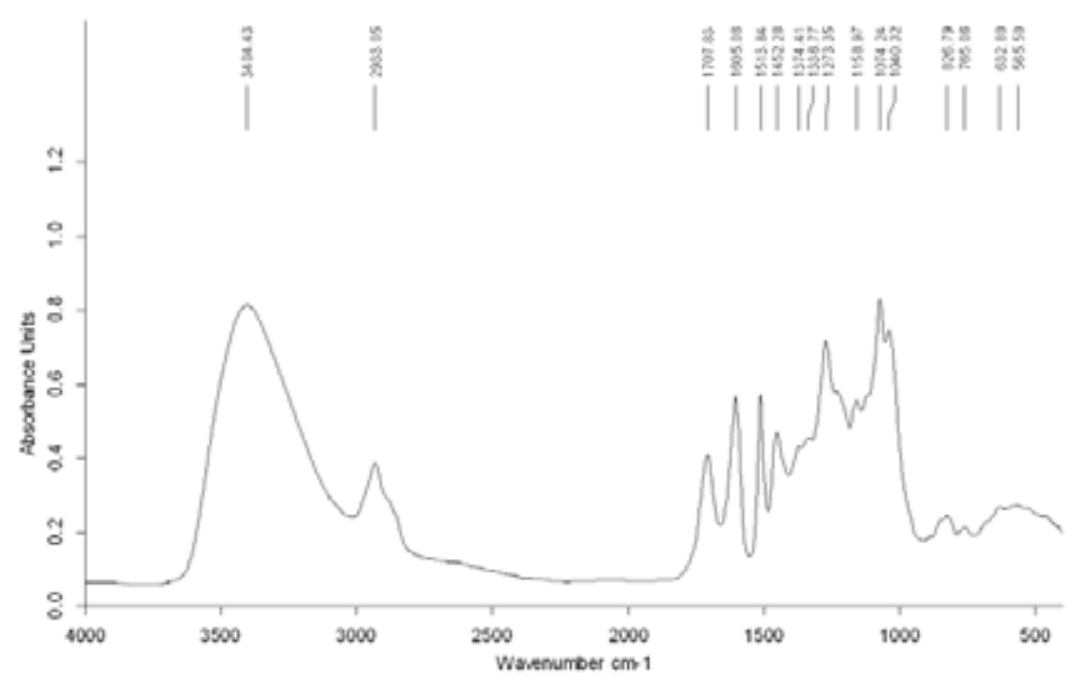

Рис. 2. ИК-спектр проантоцианидинов, выделенных из коры пихты водой

Fig. 2. IR spectrum of proanthocyanidins isolated from abies bark with water

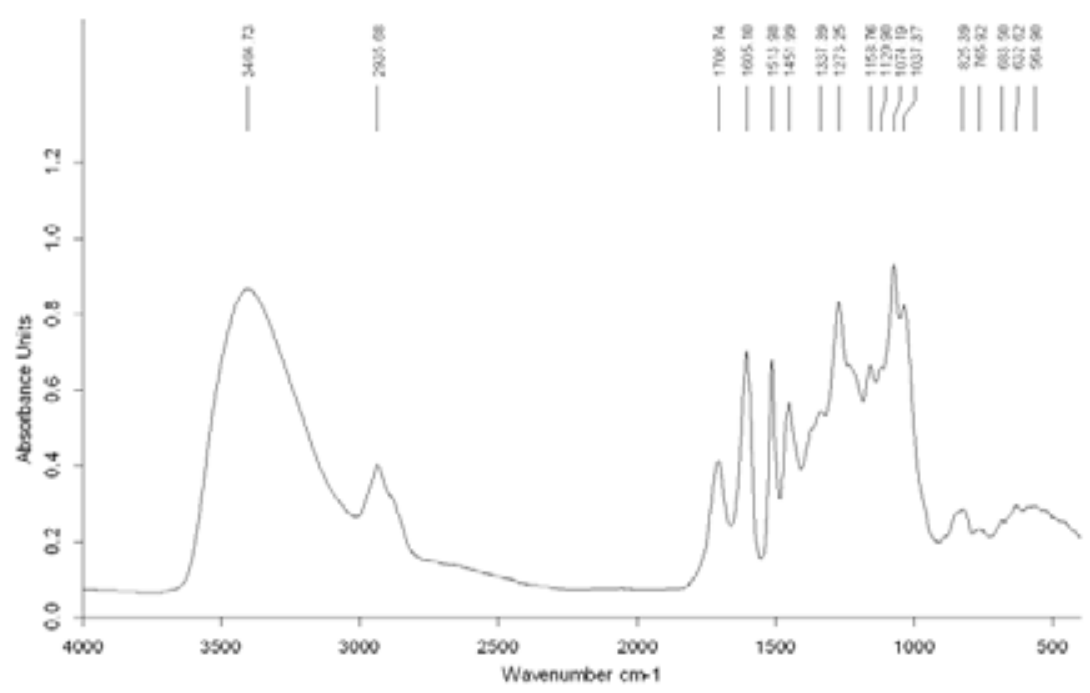

Рис. 3. ИК-спектр проантоцианидинов, выделенных из коры пихты 15\%-ным водно-этанольным раствором

Fig. 3. IR spectrum of proanthocyanidins isolated from abies bark with a $15 \%$ water-ethanol solution

$$
-609-
$$


1451-1448, 1350-1337, 1285-1273, 1158-1105, 1074-1067, 825-818, 777-766 см-1 [8]. Единственное отличие ИК-спектра проантоцианидинов из коры пихты - это появление полосы поглощения в области $1707 \mathrm{~cm}^{-1}$, характерной для карбонильной группы.

Известно, что проантоцианидины, выделенные из косточек винограда, чая и плодов диллении индийской (Dillenia indica Linn.), в положении 3 кольца С содержат остаток галловой кислоты (рис. 4). Поэтому в ИК-спектрах этих проантоцианидинов присутствует сильная полоса поглощения в области $1710 \mathrm{~cm}^{-1}[11,12]$.

Присутствие в ИК-спектрах (рис. 2, 3) проантоцианидинов коры пихты интенсивной полосы поглощения в области $1707 \mathrm{~cm}^{-1}$, характерной для $\mathrm{C}=\mathrm{O}$-группы, указывает на то, что они выделяются в виде производных галловой кислоты.

Анализ ${ }^{13} \mathrm{C}$ ЯМР-спектров проантоцианидинов коры пихты проведен с использованием литературных данных для проантоцианидинов коры сосны и другого сырья $[8,10,11]$ В ${ }^{13} \mathrm{C}$ ЯМР-спектре проантоцианидинов коры пихты (рис. 5) присутствуют сигналы всех атомов углерода, характеризующих основную структуру флавоноида.

Положения сигналов атомов углерода в ${ }^{13} \mathrm{C}$ ЯМР-спектре проантоцианидинов, выделенных из коры пихты, соответствуют литературным данным, приведенным для проантоцианидинов коры сосны [8, 9]. В области 169.9 м.д. присутствует сигнал атома углерода сложноэфирной группы $(-\mathrm{O}-\mathrm{C}=\mathrm{O})$ галлокатехина. В области 158-159 м.д. сигналы атомов углерода $\mathrm{C} 5, \mathrm{C} 7$ кольца А. Сигналы при 116 м.д. (C2', С5'), 120 (С6') и 146 м.Д. (C3', C4') принадлежат кольцу В. Сигналы атомов углерода кольца В для процианидина и продельфинидина в спектре ${ }^{13} \mathrm{C}$ ЯМР трудноразличимы и находятся в области 145 для процианидина и в области 146 м.д. для продельфинидина. В области 76-85 м.д. находятся сигналы атомов углерода 1,3-цис- и 2,3-трансизомеров проантоцианидинов. По данным, приведенным в работе [9], сигнал атома углерода в области 56.8 м.д. принадлежит атому углерода метоксильной группы $\left(-\mathrm{OCH}_{3}\right)$, а в области 62.1 м.д. - атому углерода С6 глюкозного остатка. Наличие сигнала атома углерода метоксильной группы в области 56.8 м.д. в ${ }^{13} \mathrm{C}$ ЯМР-спектре проантоцианидинов коры пихты указывает

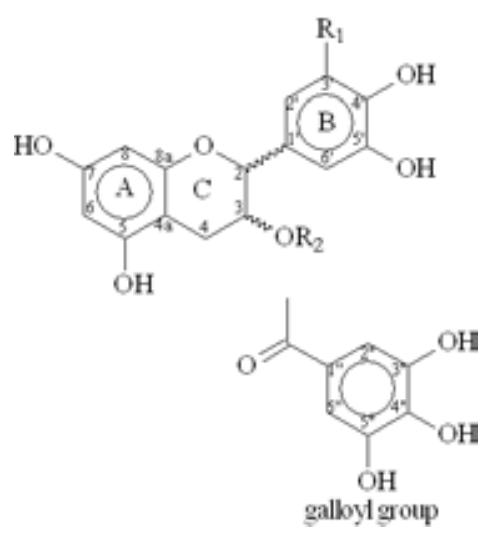

Рис. 4. Структура проантоцианидинов чая, $\mathrm{R}_{1}=\mathrm{H}, \mathrm{R}_{2}=\mathrm{H}$ - процианидины; $\mathrm{R}_{1}=\mathrm{OH}, \mathrm{R}_{2}=\mathrm{H}$, продельфинидины; $\mathrm{R}_{2}$ = галлоил - галлаты проантоцианидинов [11, 12]

Fig. 4. The structure of tea proanthocyanidins, $\mathrm{R}_{1}=\mathrm{H}, \mathrm{R}_{2}=\mathrm{H}$ - procyanidins; $\mathrm{R}_{1}=\mathrm{OH}, \mathrm{R}_{2}=\mathrm{H}$, - prodelphinidins; $\mathrm{R}_{2}=$ galloyl - gallates of proanthocyanidins $[11,12]$ 


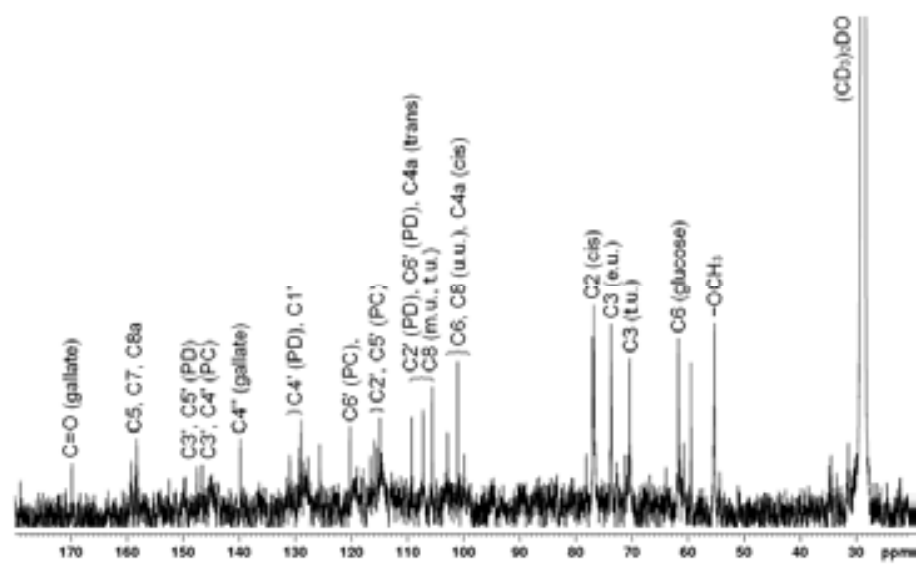

Рис. 5. ${ }^{13} \mathrm{C}$ ЯМР-спектр проантоцианидинов, выделенных из коры пихты (PC - процианидины, PD продельфинидины, m.u. - среднее звено, t.u. - концевое звено, е.u. - удлиняющее звено, u.u. - верхнее звено)

Fig. $5 .{ }^{13} \mathrm{C}$ NMR spectrum of proanthocyanidins isolated from abies bark (PC-procyanidins, $\mathrm{PD}$ - prodelphinidins, m.u. - middle unit, t.u. - terminal unit, e.u. - extension unit, u.u. - upper unit)

на присутствие в составе проантоцианидинов флавоноида пропетунидина, что согласуется с данными работы [13].

В работах, посвященных изучению проантоцианидинов коры сосны, показано, что состав флавоноидов может быть определен методом УФ-спектроскопии видимой области $[8,9,11]$. Известно, что проантоцианидины, обработанные соляной кислотой в спиртовой среде, превращаются в красные антоцианидины $[8,9]$. Структура проантоцианидинов зависит не только от природы мономерных звеньев флаван-3-ола, которые их составляют, но и от их количества и положения межфлавоноидной связи. Наиболее распространенными типами проантоцианидинов являются процианидины и продельфинидины. Мономерные звенья процианидинов - катехин и эпикатехин, а продельфинидинов - галлокатехин и эпигаллокатехин. Эти молекулы характеризуются 2,3-транс-конфигурацией заместителей С-кольца флаванолов для катехина и галлокатехина, тогда как 2,3-цис-конфигурация обнаружена для эпикатехина и эпигаллокатехина [8]. В работе [9] авторы показали, что изменение максимумов поглощения между 540 и 550 нм обусловлено изменением соотношения концентраций дельфинидин / циандин. При соотношении концентраций цианидин / дельфинидин в растворе, равном 1:1, максимум поглощения составляет 550 нм, при уменьшении концентрации дельфинидина в смеси максимум поглощения смещается к 540 нм. Максимум поглощения при $\lambda=550$ нм, наблюдаемый в спектре антоцианидинов коры пихты (рис. $6 a$ ), указывает на то, что процианидины и продельфинидины находятся в соотношении, близком к 1:1. Используя колоночную хроматографию, удалось разделить полученные антоцианидины на цианидин и дельфинидин. УФ-спектр цианидина имеет максимум поглощения в видимой области $\lambda_{\max }=546$ нм (рис. 6б), а дельфинидина $-\lambda_{\max }=556$ нм (рис. 68). 

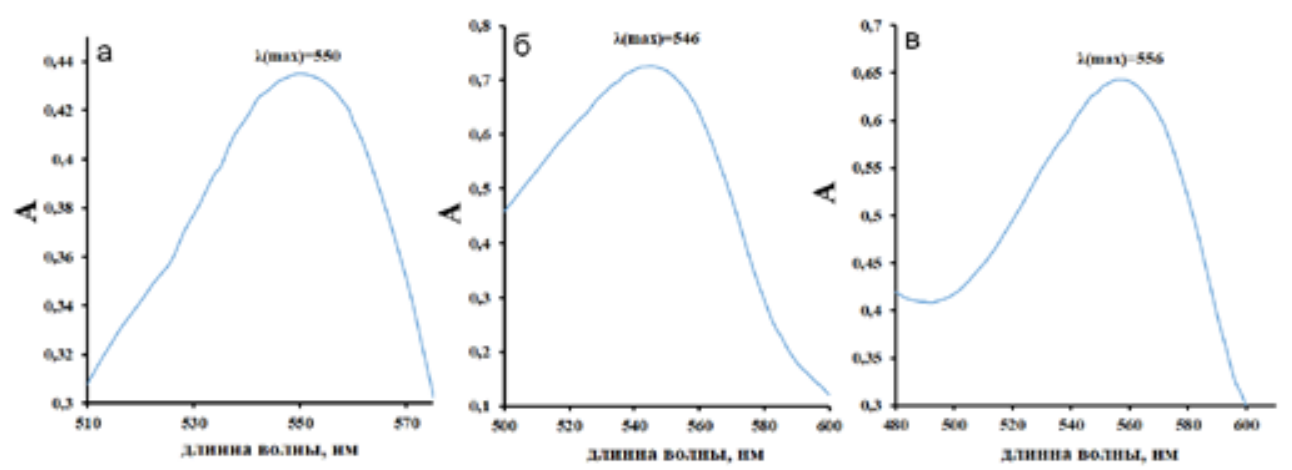

Рис. 6. УФ-спектры: смесь цианидина с дельфинидином (а), цианидин (б), дельфинидин (в)

Fig. 6. UV spectra: mixture of cyanidin with delphinidin (a), cyanidin (b), delphinidin (c)

\section{Заключение}

В работе показано, что с использованием экстракции предварительно обессмоленной коры пихты сибирской водой и 5, 10, 15, 20 \% водно-спиртовыми растворами выделены проантоцианидины с выходом 0.32-0.38 \%. Показано, что с увеличением концентрации этанола до 20 \% выход проантоцианидинов возрастает с 0.31 до $0.38 \%$, дальнейшее увеличение концентрации этанола не приводит к увеличению выхода проантоцианидинов. Методами УФ-, ИК,- ${ }^{13} \mathrm{C}$ ЯМР-спектроскопии установлено, что они в основном состоят из процианидина и продельфинидина. Наличие в ${ }^{13} \mathrm{C}$ ЯМР-спектре сигнала атома углерода метоксильной группы при 56.8 м.д. указывает на присутствие в полученных проантоцианидинах пропеонидина. Выявлено, что проантоцианидины коры пихты содержат остатки глюкозы и галловой кислоты в положении 3 кольца С. Выделенные из коры пихты проантоцианидины по своему химическому составу близки к проантоцианидинам, выделяемым из различных видов чая. В отличие от проантоцианидинов из коры сосны проантоцианидины из коры пихты содержат остатки галловой кислоты.

\section{Благодарности}

Работа выполнена в рамках проекта № 0356-2016-0505 (V.46.4.2). В работе использованы приборы Красноярского регионального центра коллективного пользования ФИЦ КНЦ СО PAH.

\section{Список литературы}

1. Bagchi D., Bagchi M., Stohs S.J., Das D.K., Ray S.D., Kuszynski C.A., Joshi S.S., Pruess H.G. Free radicals and grape seed proanthocyanidin extract: importance in human health and disease prevention. Toxicology 2000. Vol. 148(2-3), P. 187-197.

2. Haslam E. Natural polyphenols (vegetable tannins) as drugs: possible modes of action. J. Nat. Prod 1996. Vol. 59(2), P. 205-215.

3. Santos-Buelga C., Scalbert A. Proanthocyanidins and tannin-like compounds - nature, occurrence, dietary intake and effects on nutrition and health. ¡J. Sci. Food Agric 2000. Vol. 80(7), P. 1094-1117. 
4. Спрыгин В.Г., Кушнерова Н.Ф. Метод оценки и стандартизации олигомерных проантоцианидиновых комплексов, полученных из различных видов растительного сырья. Хим.фарм. журнал 2002. T. 36(3), С. 31-35. [Sprygin V.G., Kushnerova N.F. A method for evaluation and standardization of oligomeric proanthocyanidin complexes isolated from various raw plant materials. Pharm. Chem. J 2002. Vol. 36(3), P. 31-35 (In Russ.)].

5. Chang Q., Zhu M., Zuo Z., Chow M., Ho W.K.K. High-performance liquid chromatographic method for simultaneous determination of Hawthorn active components in rat plasma. J. Chromatogr. B: Biomed. Sci. Appl 2001. Vol. 760(2), P. 227-235.

6. Kim S.H., Kang K.W., Kim K.W., Kim N.D. Procyanidins in crataegus extract evoke endothelium-dependent vasorelaxation in rat aorta. Life Sciences 2000. Vol. 67(2), P. 121-131.

7. Дейнеко И.П., Фаустова Н.М. Элементный и групповой химический состав коры и древесины осины. Хим. растит. сырья 2015. №1, С. 51-62. [Deineko I.P., Faustova N.M. Element and group chemical composition of aspen bark and wood. Chemistry of plant raw materials 2015.Vol.1, P. 51-62. (In Russ.)]

8. Ku C.S., Mun S.P. Characterization of proanthocyanidin in hot water extract isolated from Pinus radiata bark. Wood Sci. Technol 2007. Vol. 41(3), P. 235-247.

9. Diouf P.N., Tibirna C.M., García-Pérez M.-E., Royer M., Dubé P., Stevanovic T. Structural elucidation of condensed tannin from Picea mariana bark. JBN. 2013. Vol. 4(3A), P. 1-8.

10. Yazaki Y. Utilization of flavonoid compounds from bark and wood: a review. Nat. Prod. Cотти. 2015. Vol. 10(3), P. 513-520.

11. Fu C., Yang D., Peh W.Y.E., Lai S., Feng X., Yang H. Structure and antioxidant activities of proanthocyanidins from Elephant apple (Dillenia indica Linn.). J. Food Sci 2015. Vol. 80(10), P. C2191-C2199.

12. Takahashi T., Nagatoishi S., Kuroda D., Tsumoto K. Thermodynamic and computational analyses reveal the functional roles of the galloyl group of tea catechins in molecular recognition. PLoS One 2018. Vol. 13(10), P. 0204856.

13. Левданский В.А., Полежаева Н.И., Макиевская А.И., Кузнецов Б.Н. Выделение и изучение состава антоцианидинов коры пихты. Химия в интересах устойчивого развития 2000. T. 8(6), C. 823-827. [Levdansky V.A., Polezhaeva N.I., Makievskaya A.I., Kuznetsov B.N. Isolation and study of the composition of fir bark anthocyanidins. Chemistry for Sustainable Development 2000. Vol. 8(6), P. 823-827. (In Russ.)] 